Research Article

\title{
Determinants of Mortality among Cervical Cancer Patients Attending in Tikur Anbessa Specialized Hospital, Ethiopia: Institutional-Based Retrospective Study
}

\author{
Mulugeta Wassie ${ }^{D},{ }^{1}$ Beletech Fentie, ${ }^{2}$ and Tseganesh Asefa ${ }^{1}$ \\ ${ }^{1}$ School of Nursing, College of Medicine and Health Sciences, University of Gondar, Gondar, Ethiopia \\ ${ }^{2}$ Department of Pediatrics and Child Health Nursing, School of Nursing, College of Medicine and Health Sciences, \\ University of Gondar, Gondar, Ethiopia
}

Correspondence should be addressed to Mulugeta Wassie; mulugeta2113@gmail.com

Received 19 March 2021; Revised 20 May 2021; Accepted 8 June 2021; Published 18 June 2021

Academic Editor: Cristina Magi-Galluzzi

Copyright (c) 2021 Mulugeta Wassie et al. This is an open access article distributed under the Creative Commons Attribution License, which permits unrestricted use, distribution, and reproduction in any medium, provided the original work is properly cited.

\begin{abstract}
Background. Globally, about 570,000 cases and 311,000 deaths of cervical cancer occurred in 2018. It was the leading cause of cancer-related deaths among women in Africa. The global mean age at death of cervical cancer was about 59 years. This study aimed to assess the determinants of cervical cancer mortality among cervical cancer patients attending in Tikur Anbessa Specialized Hospital (TASH). Methods. Institutional-based retrospective cohort study was conducted in the oncology center of TASH, Ethiopia, from March to April 2019. Data were extracted from patients' chart using structured checklist and analyzed using Stata 14.2. Cox regression was used to identify variables that affect the outcome variable. Result. From the total of 2045 reviewed medical records of cervical cancer patients, 1057 medical records were found to be complete and included in this study. The incidence of mortality among cervical cancer patients was 15.6/100/years. Mortality was significantly increased with advanced age (adjusted hazard ratio $(\mathrm{AHR})=1.02$, 95\% CI (1.01-1.03)), comorbidity (AHR $=1.8,95 \%$ CI (1.39-1.89)), being anemic $(\mathrm{AHR}=1.42,95 \% \mathrm{CI}(1.07-1.89))$, advanced stage $(\mathrm{AHR}=1.63,95 \% \mathrm{CI}(1.24-2.13))$, and being substance user $(\mathrm{AHR}=2.71,95 \%$ CI (2.08-3.53)). Conclusion. The study revealed that the incidence of mortality within the cohort was 15.6/100/years. Mortality was significantly increased with advanced age, anemia, advanced stage, comorbidity, and using substances. It is better to give special attention to patients with anemia, advanced age, advanced stage, comorbidity, and substance usage. In addition, expanding cervical cancer early screening will decrease the mortality of patients.
\end{abstract}

\section{Background}

Cancer of uterine cervix was graded in the top three malignancies, affecting females with age less than 45 years. Worldwide, nearly 570,000 cases and 311,000 deaths of cervical cancer occurred in 2018. The estimated incidence of the disease was 13.1/100,000 and it varied broadly among countries, with rates ranging from 2 to $75 / 100,000$ [1]. It is the main reason of cancer-related mortality among females in Africa. The mean age at diagnosis was 53 years, fluctuating from 44 to 68 years globally, and the average age at death was 59 years, ranging from 45 years to 76 years $[1,2]$.
The incidence and mortality rates of cervical cancer are extremely higher in regions with low and median human development index (HDI) as compared to those with very high and high HDI; indeed, death and incidence are more concentrated in low HDI countries $[3,4]$.

Early screening services of cervical cancer are changing from cytology-based to implementation of molecular screening in economically advanced regions of the world. In contrast, economically poor countries with greater magnitude of the disease continue to face monetary and logistic constraints to utilize early screening and human papillomavirus vaccine. Low-cost screening modalities, practical 
strategies, discounting cost of procurement, and delivery approaches for human papillomavirus vaccine shall be realized in low resource countries [5-7].

Regional indicators of cervical cancer are scarce in many Sub-Saharan Africa countries due to scarcities of systematic reporting and cancer registries. It may also be challenging to raise this disease as a priority problem if local actors are not aware of the condition of their home countries [6, 8-10].

Regular screening is linked with strong reduction in cervical cancer mortality and morbidity. It is expected that early screening of cervical cancer prevents $70 \%$ of cervical cancer deaths in all ages, whereas, if every women regularly attend cervical cancer screening, nearly $83 \%$ of deaths could be prevented in the females of age 35-64 years [11]. Vaccination against human papillomavirus and regular screening should be introduced and expanded to decrease morbidity and subsequent costs in both human lives and other resources [12]. In addition, early diagnosis of cervical cancer and prevention of anemia in cervical cancer patients can reduce the mortality rate of the disease $[13,14]$. Since there is limitation of data about determinants of mortality among cervical cancer patients in Ethiopia, this research will fill the gaps and be used as the base line information by health policy makers and administrators in the country.

\section{Methods and Materials}

2.1. Study Design, Period, and Area. Institutional-based retrospective cohort study was conducted in the oncology center of Tikur Anbessa Specialized Hospital (TASH), Ethiopia, from March to April 2019. TASH is the biggest referral public hospital in Ethiopia which was established in 1972. It is the training center of health professionals with undergraduate and postgraduate programs. It has over 800 beds and the beds reserved for cancer care are 20. The hospital is the only oncology center in the country and used as the only cancer registry center in Addis Ababa city.

2.2. Populations of the Study. Medical records of women diagnosed with cervical cancer in TASH oncology center were source populations and all medical records of cervical cancer patients from January 1, 2014, to December 31, 2018, were study populations. Medical records with incomplete information in addition to those not found during data collection period were excluded.

2.3. Sample Size and Sampling Procedures. The sample size of this study was all cervical cancer patients' medical records recorded from January 2014 to December 2018. Profiles of patients diagnosed between January 2014 and December 2018 in the TASH were assessed and 1057 charts that fulfilled the inclusion criteria were identified and data were collected from them. Death of cervical cancer patients was the dependent variable and sociodemographic characteristics (marital status, residential address, age at diagnosis, substance use, number of children, region, and occupation) and pathological and clinical factors (baseline anemia, histology type, stage, comorbidity, and types of comorbidities) were independent variables.

2.4. Operational Definitions. Stage at diagnosis: the revised FIGO staging for carcinoma of the vulva, cervix, and endometrium was used in this study [15].

Anemia: patients' hemoglobin level below $12.0 \mathrm{~g} / \mathrm{dl}$ was classified as anemic [16].

Comorbidity: It is the presence of any conditions (mentioned in the Carlson Comorbidity Index [17]) other than cervical cancer at diagnosis.

Substance use: patients who used one, two, or all of the three substances (cigarate, chat, and alcohol) were considered [18].

2.5. Data Collection Tools and Quality Assurance. Data were collected from patients' charts using pretested and structured checklist prepared. The checklist consisted three parts: sociodemographic factors, pathological factors, and clinical factors. Two supervisors with second degree in oncology nursing and three data collectors with first degree in nursing were involved in the data extraction process. To maintain the quality of the data, one day intensive training was given to supervisors and data collectors. In addition, pretest of the checklists was conducted by considering $5 \%$ of the total sample size to test its consistency with actual data collection and necessary corrections were made accordingly.

2.6. Data Processing and Analysis. Data were coded and then entered, edited, and cleaned using EpiData 3.1 and exported to Stata 14.2 statistical software for analysis. Frequencies, proportions, and descriptive statistics were used to describe the study population in relation to relevant variables.

Incidence of mortality was calculated for the entire study period. Cox proportional hazards regression was used to analyze independent variables affecting the outcome variable. Variables with a significance level below 0.2 in the bivariable regression were included in a multivariable regression analysis. Variables in multivariable regression with $p$ value $<0.05$ were considered to have significant interference with the outcome variable (mortality) with $95 \%$ confidence level.

2.7. Ethical Clearance. Ethical approval for this study was obtained from the Institutional Review Board of School of Nursing and Midwifery, Addis Ababa University. The letter of permission was written from the School of Nursing and Midwifery to the oncology center of TASH. Then, the cancer center chief administrator allowed us to collect the data from the cervical cancer patents medical records. The study was conducted without individual informed consent since data collection process was fully relied on chart review. 


\section{Results}

3.1. Sociodemographic Characteristics of Cervical Cancer Patients. Initially, 2045 medical records of cervical cancer patients were reviewed and 1057 medical records were found to be complete and included in this study. The mean age of the patients was 49.5 years with SD of \pm 011.8 . About $58 \%$ patients came from urban area. Nearly one-third of the patients come from Oromia reginal state and about $85.6 \%$ were unemployed. Nearly $63 \%$ of the patients were married; $17 \%$ were not substance users. Around $42 \%$ of the patients had more than three children and $3.78 \%$ had no children (Table 1).

\subsection{Clinical and Treatment-Related Characteristics of Cervical} Cancer Patients. About 57\% of the patients were diagnosed at late stage (stages III and IV). Nearly one-third of the patients had comorbidity and HIV/AIDS was the most (55.9\%) prevalent comorbidity type. Nearly half (51.18\%) of the patients were anemic and approximately $91 \%$ of the patients had squamous cell carcinoma. About half (49.2\%) of the patients received radiation therapy, and from these, about 59\% patients received palliative radiation therapy (Table 2).

3.3. Incidence of Mortality among Cervical Cancer Patients. The incidence of mortality among cervical cancer patients was 15.60 (95\% (13.96-17.45)) per 100 person-years with 3.7 years (44.4 months) of median survival time. The overall survival was $54.8 \%$ in the five years of follow-up period. The five-year survival of patients with late and early stages was $44.93 \%$ and $69.89 \%$, respectively, whereas the five-year survival of patients with advanced and early age was $38.95 \%$ and $85.86 \%$. About $30.47 \%$ and $61 \%$ of substance users and nonusers, $40.34 \%$ and $73.45 \%$ of anemic and nonanemic patients, $36.24 \%$ and $65.62 \%$ comorbid and noncomorbid patients, respectively, survived at least for five years.

About $43.9 \%$ of patients within age group of $\geq 60$, but only $7.61 \%$ of patients with the age group $\leq 30$, had died. Nearly $30 \%$ of rural dwellers, $30 \%$ of unemployed, $53 \%$ substance users, and $85 \%$ of patients without children died in the current study (Table 1). Nearly $38 \%$ of the patients with late stage (stages III and IV) and about half (46.8\%) of the patients with comorbidity, $42.5 \%$ with anemia, $33 \%$ treated with chemo and radiation therapy, and $37 \%$ patients who got palliative radiation therapy had died in this cohort (Table 2).

3.4. Determinants of Mortality among Cervical Cancer Patients. Independent variables were individually regressed against the outcome variable and the variables with the $p$ value $<0.2$ were included in the multivariable Cox
TABLE 1: Sociodemographic characteristics of cervical cancer patients and mortality related to these characteristics in TASH.

\begin{tabular}{|c|c|c|c|c|}
\hline \multirow[b]{2}{*}{ Variables } & \multirow[b]{2}{*}{ Category } & \multirow[b]{2}{*}{$\begin{array}{c}\text { Response } \\
N(\%)\end{array}$} & \multicolumn{2}{|c|}{ Mortality } \\
\hline & & & $\begin{array}{c}\text { Yes } \\
N(\%) \\
\end{array}$ & $\begin{array}{c}\text { No } \\
N(\%) \\
\end{array}$ \\
\hline \multirow{5}{*}{ Age } & $<30$ & $92(8.70)$ & $7(7.61)$ & $85(92.39)$ \\
\hline & $30-49$ & $219(20.72)$ & $36(16.44)$ & $\begin{array}{c}183 \\
(83.56)\end{array}$ \\
\hline & $41-49$ & $\begin{array}{c}262 \\
(24.79)\end{array}$ & $70(26.72)$ & $\begin{array}{c}192 \\
(73.28)\end{array}$ \\
\hline & $50-59$ & $245(23.18)$ & $91(37.14)$ & $\begin{array}{c}154 \\
(62.86)\end{array}$ \\
\hline & $\geq 60$ & $239(22.61)$ & $\begin{array}{c}105 \\
(43.93) \\
\end{array}$ & $\begin{array}{c}134 \\
(56.07) \\
\end{array}$ \\
\hline \multirow{2}{*}{ Residence } & Urban & 614 (58.09) & $\begin{array}{c}176 \\
(28.66)\end{array}$ & $\begin{array}{c}438 \\
(71.34)\end{array}$ \\
\hline & Rural & $443(41.91)$ & $\begin{array}{c}133 \\
(30.02) \\
\end{array}$ & $\begin{array}{c}310 \\
(69.98) \\
\end{array}$ \\
\hline \multirow{6}{*}{ Region } & Amhara & $281(26.58)$ & $94(33.45)$ & $\begin{array}{c}187 \\
(66.55)\end{array}$ \\
\hline & Oromia & $341(32.26)$ & 97 (28.45) & $\begin{array}{c}244 \\
(71.55)\end{array}$ \\
\hline & Tigray & $30(2.84)$ & $10(33.33)$ & $20(66.67)$ \\
\hline & SNNP & 95 (8.99) & $33(34.74)$ & $62(65.26)$ \\
\hline & Addis Ababa & $\begin{array}{c}280 \\
(26.49)\end{array}$ & $68(24.29)$ & $\begin{array}{c}212 \\
(75.71)\end{array}$ \\
\hline & Others & $30(2.84)$ & $7(23.33)$ & $23(76.67)$ \\
\hline \multirow{2}{*}{ Occupation } & Unemployed & $\begin{array}{c}905 \\
(85.62)\end{array}$ & $\begin{array}{c}275 \\
(30.39)\end{array}$ & $\begin{array}{c}630 \\
(69.61)\end{array}$ \\
\hline & Employed & $152(14.38)$ & $34(22.37)$ & $\begin{array}{c}118 \\
(77.63) \\
\end{array}$ \\
\hline \multirow{2}{*}{$\begin{array}{l}\text { Marital } \\
\text { status }\end{array}$} & Single & $\begin{array}{c}392 \\
(37.09)\end{array}$ & $\begin{array}{c}111 \\
(28.32)\end{array}$ & $\begin{array}{c}281 \\
(71.68)\end{array}$ \\
\hline & Married & $665(62.91)$ & $\begin{array}{c}198 \\
(29.77) \\
\end{array}$ & $\begin{array}{c}467 \\
(70.23) \\
\end{array}$ \\
\hline \multirow[b]{2}{*}{ Substance } & User & $182(17.22)$ & $97(53.30)$ & $85(46.70)$ \\
\hline & Nonuser & $\begin{array}{c}875 \\
(82.78) \\
\end{array}$ & $\begin{array}{c}212 \\
(24.23) \\
\end{array}$ & $\begin{array}{c}663 \\
(75.77) \\
\end{array}$ \\
\hline \multirow{5}{*}{ Children } & None & $40(3.78)$ & $34(85.00)$ & $16(15.00)$ \\
\hline & One & $69(6.53)$ & $24(34.78)$ & $45(65.22)$ \\
\hline & Two & $147(13.91)$ & $49(33.33)$ & $98(66.67)$ \\
\hline & Three & $361(34.1)$ & $\begin{array}{c}122 \\
(33.80)\end{array}$ & $\begin{array}{c}239 \\
(66.20)\end{array}$ \\
\hline & More than 3 & $440(41.63)$ & $\begin{array}{c}108 \\
(24.55) \\
\end{array}$ & $\begin{array}{c}332 \\
(75.45) \\
\end{array}$ \\
\hline
\end{tabular}

regression. In bivariable analysis, age, comorbidity, anemia, stage, substance, and aim of radiation therapy were associated with the outcome variable at $p$ value $<0.2$. But in multivariable analysis, age, substance, anemia, stage of cancer, and comorbidity were significantly associated with the outcome variable at $p$ value $<0.05$ with $95 \%$ CI.

Aged patients had died about 1.02 (95\% CI (1.01-1.03)) times more than their counterparts. Patients with comorbidity died 1.80 (95\% CI (1.39-1.89)) times more than those 
TABLE 2: Clinical and treatment-related characteristics and mortality related to these characteristics among cervical cancer patients in TASH.

\begin{tabular}{|c|c|c|c|c|}
\hline \multirow[b]{2}{*}{ Variables } & \multirow[b]{2}{*}{ Category } & \multirow[b]{2}{*}{$\begin{array}{c}\text { Response } \\
N(\%)\end{array}$} & \multicolumn{2}{|c|}{ Mortality } \\
\hline & & & $\begin{array}{c}\text { Yes } \\
N(\%)\end{array}$ & $\begin{array}{c}\text { No } \\
N(\%)\end{array}$ \\
\hline \multirow{2}{*}{ Stage } & Early & $457(43.24)$ & $81(17.72)$ & $376(82.28)$ \\
\hline & Late & $600(56.76)$ & $228(38.00)$ & $372(62.00)$ \\
\hline \multirow{2}{*}{ Comorbidity } & Yes & $344(32.54)$ & $161(46.80)$ & $183(53.20)$ \\
\hline & No & $713(67.46)$ & $148(20.76)$ & $565(79.24)$ \\
\hline \multirow{3}{*}{ Types of comorbidities } & HIV & $194(55.91)$ & $99(51.03)$ & $95(48.97)$ \\
\hline & Hypertension & $79(22.77)$ & $32(40.51)$ & $47(59.49)$ \\
\hline & Others & $74(21.33)$ & $31(41.89)$ & $43(58.11)$ \\
\hline \multirow{2}{*}{ Anemia } & Yes & $541(51.18)$ & $230(42.51)$ & $311(57.49)$ \\
\hline & No & $516(48.82)$ & $79(15.31)$ & $437(84.69)$ \\
\hline \multirow{2}{*}{ Histopathology } & Squamous cell & $959(90.73)$ & $279(41.89)$ & $680(70.91)$ \\
\hline & Adenocarcinoma & $98(9.27)$ & $30(30.61)$ & $68(69.39)$ \\
\hline \multirow{6}{*}{ Treatment initiated } & Sur and chemo & $17(1.60)$ & $4(23.53)$ & $13(76.47)$ \\
\hline & Chemo & $19(1.80)$ & $3(15.79)$ & $16(84.21)$ \\
\hline & Radiotherapy & $520(49.2)$ & $147(28.27)$ & $373(71.73)$ \\
\hline & Chemo and RT & $375(35.4)$ & $125(33.33)$ & $250(66.67)$ \\
\hline & Sur and RT & $111(10.5)$ & $23(20.72)$ & $88(79.28)$ \\
\hline & Chemo + Sur + RT & $15(1.4)$ & $7(46.67)$ & $8(53.33)$ \\
\hline \multirow{3}{*}{ Aim of $R T$} & Radical & $388(36.71)$ & $75(19.33)$ & $313(80.67)$ \\
\hline & NO RT & $46(4.35)$ & $5(10.87)$ & $41(89.13)$ \\
\hline & Palliative & $623(58.94)$ & $229(36.76)$ & $394(63.24)$ \\
\hline
\end{tabular}

Note: Sur = surgical treatment; chemo = chemotherapy; RT = radiation therapy.

without comorbidity and anemic patients died 1.42 (95\% CI (1.07-1.89)) times more than nonanemic patients.

Study patients with advanced stage died 1.63 (95\% CI (1.24-2.13)) times more than with early stages, whereas substance users died 2.71 (95\% CI (2.08-3.53)) times more than nonusers (Table 3 ).

\section{Discussion}

The current study aimed to identify determinants of mortality among cervical cancer patients attending in Tikur Anbessa Specialized Hospital oncology center. The incidence rate of mortality among cervical cancer patients was 15.6 per 100 person-years in the current study. This finding is lower than the study conducted in Brazil with mortality rate of $18.9 \%$ [19], but in line with Nigerian finding with $14.8 \%$ incidence rates of mortality [20]. The disagreement with Brazilian finding might be due to socioeconomic differences of the study participants, study period, and sample size differences.

The current study revealed that aged cervical cancer patients' mortality was higher than their counterparts. This is consistent with the study conducted in China [21]. This similarity could be due to the fact that as age increases, cervical cancer survival decreases $[22,23]$. But the finding is inconsistent with the study conducted in Colombia, which revealed that more cervical cancer patients died in the age groups of 20 and 49 due to young families' economic status [24]. This difference might be due to study setting, study time, and socioeconomic differences of the study participants.

Cervical cancer patients with comorbidity had died about two times more than those without comorbidity. This finding is supported by the studies conducted in Australia [25], New Zealand [26], and Italy [27]. This consistency could be as comorbidities can limit the opportunities of the treatment options, increase the risk of treatment complications, and related with discontinuation or nonadherence of treatment [28]. Furthermore, comorbidities decrease the cancer treatment effectiveness and increase comorbidityassociated death [17].

Patients who were anemic died more than nonanemic patients. This finding is supported by studies done in Nigeria [29] and Ethiopia [30]. This could be as anemia is more associated with hypoxia, which reduces tumor sensitivity to antiblastic treatments and increase mortality [31, 32].

Patients who presented with advanced stage died more than those with early stage. This result is in line with the studies conducted in New Zealand $[33,34]$. The increment of mortality could be as the cancer stage getting advanced, its metastasis rate could be increased and these factors might decrease the probability to respond a treatment and lead to death [35].

Substance users in the current study died about three times more than nonusers. The possible justification of this finding could be as substances residue in cervical mucosa lead to damage in the DNA of cervical cells and these make the immune system less effective to fight against cervical cancer [36-38].

\section{Limitations}

Even though this study involved relatively large sample size, cause-specific mortality incidence was not determined due to lack of data on specific cause of death. This may 
TABLE 3: Results of bivariable and multivariable Cox regression analysis of cervical cancer patients at TASH, Ethiopia $(n=1057)$.

\begin{tabular}{|c|c|c|c|c|c|}
\hline Variables & Category & CHR (95\% CI) & $p$ value & AHR (95\% CI) & $p$ value \\
\hline Age & & $1.01(1.00-1.02)$ & $0.007^{*}$ & $1.02(1.01-1.03)$ & $0.001^{* *}$ \\
\hline \multirow{2}{*}{ Comorbidity } & Yes & $2.51(2.01-3.14)$ & $<0.001^{*}$ & 1.80 (1.39-1.89) & $<0.001^{* *}$ \\
\hline & No & 1.0 & & 1.0 & \\
\hline \multirow{2}{*}{ Anemia } & Yes & $2.05(1.59-2.66)$ & $<0.001^{*}$ & $1.42(1.07-1.89)$ & $0.015^{* *}$ \\
\hline & No & 1.0 & & 1.0 & \\
\hline \multirow{2}{*}{ Stage } & Early & 1 & & 1.0 & \\
\hline & Advanced & $2.03(1.57-2.61)$ & $<0.001^{*}$ & $1.63(1.24-2.13)$ & $<0.001^{* *}$ \\
\hline \multirow{2}{*}{ Substance } & User & $3.72(2.92-4.75)$ & $<0.001^{*}$ & $2.71(2.08-3.53)$ & $<0.001^{* *}$ \\
\hline & Nonuser & 1.0 & & 1.0 & \\
\hline \multirow{3}{*}{ Aim of $R T$} & Radical & 1.0 & & 1.0 & \\
\hline & No radiation & $0.55(0.23-1.39)$ & 0.209 & $0.58(0.23-1.45)$ & 0.247 \\
\hline & Palliative & $1.82(1.40-2.37)$ & $<0.001^{*}$ & $1.17(0.88-1.55)$ & 0.279 \\
\hline
\end{tabular}

Note: ${ }^{*}$ Variables associated with the outcome variable in bivariable analysis; ${ }^{* *}$ variables significantly associated with the outcome variable in multivariable analysis at $95 \%$ level of significance $(p<0.05) ; 1=$ reference category.

overestimate the incidence of mortality rate. Information such as educational level, history of abortion, and age at first marriage were not recorded and not included in the study. Finally, the information was not recorded for the purpose of research that caused many chars with incomplete information.

\section{Conclusion}

The study revealed that the incidence of mortality among cervical cancer patients was 15.6 per 100 person-years. Mortality of cervical cancer patients was significantly increased with being advanced age, anemic, advanced stage, and comorbid and using substances. It is better to give special attention to patients with anemia, advanced age, advanced stage, comorbidity, and substance usage. Cervical cancer early screening and educating patients about bad effects of using substances can decrease mortality.

\section{Abbreviations}

AHR: Adjusted hazard ratio

CHR: Crude hazard ratio

HIV: Human immunodeficiency virus

FIGO: International Federation of Gynecology and Obstetrics

TASH: Tikur Anbessa Specialized Hospital.

\section{Data Availability}

Data will be available upon reasonable request from the corresponding author.

\section{Ethical Approval}

Ethical approval for this study was obtained from the Institutional Review Board (IRB) of School of Nursing and Midwifery, Addis Ababa University. The letter of permission was written from School of Nursing and Midwifery to the oncology center of TASH. Then, the oncology center chief administrator permitted the authors to extract the data from the patients' chart. The study was conducted without individual informed consent since data extraction fully relied on chart review.

\section{Disclosure}

This work was conducted as fulfilment of master program in the specialty of oncology nursing at the College of Health Sciences, Addis Ababa University.

\section{Conflicts of Interest}

The authors declare that they have no conflicts of interest.

\section{Authors' Contributions}

M. W. conceptualized the study and was involved in the design, analysis, interpretation, report, and manuscript writing. B. F. and T. A. made substantial contribution to conception, analysis and interpretation of data, drafting the manuscript, and critical revision for important intellectual content. All the authors read and approved the final manuscript.

\section{Acknowledgments}

The authors' gratitude goes to School of Nursing and Midwifery, College of Health Sciences, Addis Ababa University, which allowed them to conduct this research. The authors duly acknowledge the University of Gondar for giving the opportunity of paid study leave. The authors also thank the Tikur Anbessa Specialized Hospital managers and all cancer center staff.

\section{References}

[1] M. Arbyn, E. Weiderpass, L. Bruni et al., "Estimates of incidence and mortality of cervical cancer in 2018: a worldwide analysis," The Lancet Global Health, vol. 8, no. 2, pp. e191-e203, 2020.

[2] M. Arbyn, X. Castellsagué, S. De Sanjosé et al., "Worldwide burden of cervical cancer in 2008," Annals of Oncology, vol. 22, no. 12, pp. 2675-2686, 2011. 
[3] G. K. Singh, R. E. Azuine, and M. Siahpush, "Global inequalities in cervical cancer incidence and mortality are linked to deprivation low socioeconomic status and human development," International Journal of $M C H$ and AIDS, vol. 1, no. 1, pp. 17-30, 2012.

[4] K. Mansori, "Global inequalities in cervical cancer incidence and mortality," Middle East Journal of Cancer, vol. 9, no. 3, 2018.

[5] S. Pimple, G. Mishra, and S. Shastri, "Global strategies for cervical cancer prevention," Current Opinion in Obstetrics \& Gynecology, vol. 28, no. 1, pp. 4-10, 2016.

[6] H. Nagai and Y. H. Kim, "Cancer prevention from the perspective of global cancer burden patterns," Journal of Thoracic Disease, vol. 9, no. 3, pp. 448-451, 2017.

[7] G. M. Ginsberg, T. T.-T. Edejer, J. A. Lauer, and C. Sepulveda, "Screening prevention and treatment of cervical cancer-a global and regional generalized cost-effectiveness analysis," Vaccine, vol. 27, no. 43, pp. 6060-6079, 2009.

[8] J. O. Parkhurst and M. Vulimiri, "Cervical cancer and the global health agenda: insights from multiple policy-analysis frameworks," Global Public Health, vol. 8, no. 10, pp. 1093-1108, 2013.

[9] D. Echelman and S. Feldman, "Management of cervical precancers: a global perspective," Hematology/Oncology Clinics of North America, vol. 26, no. 1, pp. 31-44, 2012.

[10] L. A. Torre, "Global cancer statistics," CA: A Cancer Journal for Clinicians, vol. 65, no. 2, pp. 87-108, 2012.

[11] R. Landy, F. Pesola, A. Castañón, and P. Sasieni, "Impact of cervical screening on cervical cancer mortality: estimation using stage-specific results from a nested case-control study," British Journal of Cancer, vol. 115, no. 9, pp. 1140-1146, 2016.

[12] A. Hailu and D. H. Mariam, "Patient side cost and its predictors for cervical cancer in Ethiopia: a cross sectional hospital based study," BMC Cancer, vol. 13, no. 1, pp. 69-78, 2013.

[13] M. Wassie, A. Aemro, and B. Fentie, "Prevalence and associated factors of baseline anemia among cervical cancer patients in Tikur Anbesa Specialized Hospital Ethiopia," BMC Women's Health, vol. 21, no. 1, p. 36, 2021.

[14] M. Wassie and B. Fentie, "Prevalence of late-stage presentation and associated factors of cervical cancer patients in Tikur Anbesa Specialized Hospital Ethiopia: institutional based cross-sectional study," Infectious Agents and Cancer, vol. 16, no. 1, p. 30, 2021.

[15] S. Pecorelli, "Revised FIGO staging for carcinoma of the vulva cervix and endometrium," International Journal of Gynecology \& Obstetrics, vol. 105, no. 2, pp. 103-104, 2009.

[16] I. CSA, Ethiopia Demographic and Health Survey 2016: Key Indicators Report, CSA and ICF, Addis Ababa, Rockville, 2016.

[17] M. Charlson and W. Foley, "Charlson comorbidity index: chart review version," Clinical Epidemiology, vol. 9, pp. 311$320,2018$.

[18] O. W. Health, Promoting Mental Health: Concepts Emerging Evidence Practice: A Report of the World Health Organization, Foundation and the University of Melbourne, Carlton, Australia, 2005

[19] D. B. Vale, C. Sauvaget, R. Muwonge et al., "Disparities in time trends of cervical cancer mortality rates in Brazil," Cancer Causes \& Control, vol. 27, no. 7, pp. 889-896, 2016.

[20] H. I. Anyasi and A. M. Foss, "A comparative analysis of cervical cancer prevention between Nigeria and Nordic countries that have experienced a decline in cervical cancer incidence," International Health, 2020.

[21] P.-L. Du, K.-S. Wu, J.-Y. Fang et al., "Cervical cancer mortality trends in China 1991-2013 and predictions for the future,"
Asian Pacific Journal of Cancer Prevention, vol. 16, no. 15, pp. 6391-6396, 2015.

[22] M. C. White, D. M. Holman, J. E. Boehm, L. A. Peipins, M. Grossman, and S. Jane Henley, "Age and cancer risk," American Journal of Preventive Medicine, vol. 46, no. 3, pp. S7-S15, 2014.

[23] A. S. Rustagi, A. Kamineni, S. Weinmann, S. D. Reed, P. Newcomb, and N. S. Weiss, "Cervical screening and cervical cancer death among older women: a population-based case-control study," American Journal of Epidemiology, vol. 179, no. 9, pp. 1107-1114, 2014.

[24] S. Bermedo-Carrasco and C. L. Waldner, "The role of sociodemographic factors in premature cervical cancer mortality in Colombia," BMC Public Health, vol. 16, no. 1, pp. 1-13, 2016.

[25] A. Diaz, P. D. Baade, P. C. Valery et al., "Comorbidity and cervical cancer survival of Indigenous and non-Indigenous Australian women: a semi-national registry-based cohort study (2003-2012)," PLoS One, vol. 13, no. 5, Article ID e0196764, 2018.

[26] J. B. Lew, K. Simms, M. Smith, H. Lewis, H. Neal, and K. Canfell, "Effectiveness modelling and economic evaluation of primary HPV screening for cervical cancer prevention in New Zealand," PLoS One, vol. 11, no. 5, Article ID e0151619, 2016.

[27] G. Ferrandina, A. Lucidi, A. Paglia et al., "Role of comorbidities in locally advanced cervical cancer patients administered preoperative chemoradiation: impact on outcome and treatment-related complications," European Journal of Surgical Oncology (EJSO), vol. 38, no. 3, pp. 238-244, 2012.

[28] N. Brewer, "Does comorbidity explain the ethnic inequalities in cervical cancer survival in New Zealand? A retrospective cohort study," BMC Cancer, vol. 11, no. 1, pp. 1-7, 2011.

[29] J. Musa, J. Nankat, C. J. Achenbach et al., "Cervical cancer survival in a resource-limited setting-North Central Nigeria," Infectious Agents and Cancer, vol. 11, no. 1, pp. 15-17, 2016.

[30] M. Gizaw, A. Addissie, S. Getachew et al., "Cervical cancer patients presentation and survival in the only oncology referral hospital Ethiopia: a retrospective cohort study," Infectious Agents and Cancer, vol. 12, no. 1, pp. 61-67, 2017.

[31] M. Hockel and P. Vaupel, "Tumor hypoxia: definitions and current clinical biologic and molecular aspects," JNCI Journal of the National Cancer Institute, vol. 93, no. 4, pp. 266-276, 2001.

[32] C. Madeddu, G. Gramignano, G. Astara et al., "Pathogenesis and treatment options of cancer related anemia: perspective for a targeted mechanism-based approach," Frontiers in Physiology, vol. 9, p. 1294, 2018.

[33] M. Wassie, Z. Argaw, Y. Tsige, M. Abebe, and S. Kisa, "Survival status and associated factors of death among cervical cancer patients attending at Tikur Anbesa Specialized Hospital Addis Ababa Ethiopia: a retrospective cohort study," BMC Cancer, vol. 19, no. 1, pp. 1221-1311, 2019.

[34] A. M. Grjibovski, D. Dubovichenko, S. Saduakassova et al., "Incidence mortality and determinants of survival from cervical cancer in Northwest Russia: a registry-based cohort study," International Health, vol. 10, no. 2, pp. 92-99, 2018.

[35] D. G. Mitchell, B. Snyder, F. Coakley et al., "Early invasive cervical cancer: tumor delineation by magnetic resonance imaging computed tomography and clinical examination verified by pathologic results in the ACRIN 6651/GOG 183 Intergroup Study," Journal of Clinical Oncology, vol. 24, no. 36, pp. 5687-5694, 2006.

[36] M. H. Einstein, J. T. Schiller, R. P. Viscidi et al., "Clinician's guide to human papillomavirus immunology: knowns and 
unknowns," The Lancet Infectious Diseases, vol. 9, no. 6, pp. 347-356, 2009.

[37] J. R. Lechien, G. Descamps, I. Seminerio et al., "HPV involvement in the tumor microenvironment and immune treatment in head and neck squamous cell carcinomas," Cancers, vol. 12, no. 5, p. 1060, 2020.

[38] J. Marx, "Cancer research: inflammation and cancer: the link grows stronger," Science, vol. 306, no. 5698, pp. 966-968, 2004. 